\title{
Children's Ability to Recognise Toxic and Non-Toxic Fruits
}

\author{
Jana Fančovičová \\ Trnava University, Trnava, SLOV AKIA \\ Pavol Prokop \\ Trnava University, Trnava \& Institute of Zoology, Bratislava, SLOV AKIA
}

Received 17 October 2010; accepted 29 March 2011

\begin{abstract}
Children's ability to identify common plants is a necessary prerequisite for learning botany. However, recent work has shown that children lack positive attitudes toward plants and are unable to identify them. We examined children's (aged 10-17) ability to discriminate between common toxic and non-toxic plants and their mature fruits presented in a colourful PowerPoint presentation. We found that toxic plants were less well known than plants with edible fruits and those younger children were more willing to consume toxic fruits than older children. Children abilities to distinguish toxic and non-toxic plants did not increase with age suggesting that school does not play the primary role in building children's knowledge about toxic plants. This study supports the idea that children's knowledge about plants is limited and more effort should be dedicated to teaching about toxic plants that are often harmful especially to inexperienced children.
\end{abstract}

Keywords: Children, Fruits, Plants, Risk, Toxicity

\section{INTRODUCTION}

Many plants, animals and microorganisms contain substances which can be toxic to humans. Toxic plants are everywhere around us, they grow in different places, and thus at least some of them are potentially harmful to humans. Despite preventative efforts, more than one million of pupils younger than 6 year olds are poisoned in America every year (Litovitz et al., 1992). Children aged 2 are relatively frequently consuming poisonous plants and/or chemicals (Jacobson et al., 1989). Importantly, the risk of recurrent poisoning is about 30\% (Litovitz et al., 1989).

Recent records from the National toxicology information centre of Slovakia (NTIC) show that, intoxication by poisonous plants has increased. Plačková et al. (2006) state that accidental poisoning of children by ingestion of plants causes more than $50 \%$ of all

Correspondence to: Jana Fančovičová, Assistant Professor of Biology Education, Department of Biology, Faculty of Education, Trnava University, Priemyselná 4, PO Box 9, 91843 Trnava, SLOV AKIA

E-mail:fankaj@gmail.com poisoning cases in Slovakia. Lack of children' as well as parents' knowledge (Polakoff, Lacouture, \& Lovejoy, 1984), the attractive appearance of plants (colour, fashion, fragrance) and similarity between some toxic and nontoxic plants (Plačková, Cagáňová, \& Kresánek, 2006) are probably the most frequent reasons for such incidents. Consequences of intoxications are varied in their harm (but include activating irritation of the digestive system, contact dermatitis or allergic responses) (e.g. Plačková, Cagáňová, \& Kresánek, 2006).

It is suggested that low identification skills of plants are responsible for consumption of some poisonous plants by children. This assumption makes sense considering that the risk of toxic plant consumption is highest among younger children who are probably less aware about the toxicity of some plants or their fruits. Although there is lack of data on school children, we hypothesize that girls might be expected to be better at plant identification, because girls have been shown to have a greater interest in plants (Dawson, 1983; Lohr et al., 2004; Hong, Shim, \& Chang, 1998; Gatt et al., 2007; Prokop et al., 2007a, b; Schussler \& Olzak, 2008). Recent research confirmed that girls have better knowledge of plants than boys (Fančovičová \& Prokop, 


\section{State of the literature}

- Many studies show that low identification skills of plants are responsible for consumption of poisonous plants by children.

- The risk of consumption is highest among younger children who are less aware about the toxicity of some plants or their fruits.

- Researches confirm better knowledge of girls about plants and their greater interest in plant than boys.

- Going to the nature influences ability of children to determine plants.

\section{Contribution of this paper to the literature}

- The study supports that children have few experiences with toxic plants and low ability to distinguish between toxic and non-toxic plants.

- Younger children are more willing to eat toxic fruits and have less experience with toxic fruits.

- Girls have the same identification abilities and experience with toxic plants as boys does.

- Experience with toxic fruits correlate with children confidence to determinate plants.

in press). Familiarity, going to the nature also influences

children's ability to identify plants (LindemannMatthies, 2005), so children who experience environment more frequently would have more experience with plants and, consequently, these children would be more knowledgeable about plants.

To date, surprisingly, little is known about children knowledge of toxic plants. Few indirect evidences suggest that school age children have poor plant identification skills. Bebbington (2005) for example found that only a few children were able to name more than three very common wild flowers in the UK suggesting that learners' knowledge about basic plant species is poor. Surprisingly we are not aware of any study focused specifically on children's abilities to recognize toxic and non-toxic plants or fruits. According to the Slovakian biology curriculum, children at age 11/12 (Grade 6) should be able to identify seven species of toxic plants, out of which three are commonly eaten by children and cause intoxications (Plačková, Cagáñová, \& Kresánek, 2006). Unfortunately, the ability of Slovakian children to identify plants in general, and their abilities to recognize poisonous and edible fruits have never been investigated. Deeper insight into children's knowledge of plants might be of special interest for curriculum developers and science teachers because answers on these questions would significantly contribute to development of biology textbooks and/or improving education strategies in biology in the future.

This study was designed to examine children's abilities to distinguish toxic and non-toxic (mostly native) fruits in Slovakia. In contrast to traditional studies measuring knowledge, in which multiple choice tests or open/ended questions are used, we stimulated children to answer our questions by showing colourful pictures of plants and their fruits with a PowerPoint presentation. This approach allow more precise examination, because children are not given only abstract words on sheets of paper, but questions are supported with colourful pictures of plants and their ripe fruits.

We predicted that:

1) Females will have better plant identification skills than males.

2) Younger children will be more willing to consume toxic fruits compared to their older counterparts.

3) Children will show more experience with non-toxic plants compared to toxic plants and consequently non-toxic plants will be more often identified correctly than toxic plants.

\section{METHODS}

\section{Participants}

One hundred and seventeen randomly selected elementary school pupils (aged 10-17, 62\% females) from two Slovakian elementary schools were involved in research during their free lesson. Data collection took place in December 2009.

\section{Research instruments and procedure}

We presented a Power point presentation with twenty different colour pictures of plants and their mature fruits. All pictures were freely downloaded from Google. Each picture was of high quality, and contained both leaves and fruits of a particular plant. Nine plants were toxic and eleven were non-toxic. Selection of plants followed two criteria: 1. availability (rare plants were not included) and 2. incidence of intoxication (more risky plants based on incidence of intoxication published by Plačková et al. 2006 were included).

We adjusted picture sizes to a uniform magnification scale. Pictures had similar contrast and brightness. The pictures were presented in random order. Each picture was presented for 1 minute. During this time, participants rated (a) willingness to eat fruits (Willingness) (Would you eat fruits of this plant?), (b) whether they thought that their identification is correct (Confidence) (Do you know the species of the plant?), (c) experiences with plants (Experiences) (Have you ever seen this plant?), (d) perceived toxicity of the fruit 
Table 1. Ranked, mean success in discriminating of toxic and non-toxic fruits

\begin{tabular}{lccc}
\hline Species & Toxic(TF)/ & & \\
Non-toxic(NTF) & Mean score & SE \\
\hline 1. Red raspberry (Rubus idaeus) & NTF & 1.00 & 0.03 \\
2. Wild briar (Dog rose)(Rosa canina) & NTF & 0.97 & 0.03 \\
3. Japanese Cherry (Prunus serrulata) & NTF & 0.96 & 0.03 \\
4. Blackberry (Rubus fruticosus) & NTF & 0.93 & 0.03 \\
5. White currant (Ribes niveum) & NTF & 0.82 & 0.03 \\
6. Red currant (Ribes rubrum) & NTF & 0.78 & 0.03 \\
7. Bilberries (Vaccinium myrtillus) & NTF & 0.50 & 0.03 \\
8. English yew (European yew) (Taxus baccata) & TF & 0.20 & 0.03 \\
9. White mulberry (Morus alba) & NTF & 0.16 & 0.03 \\
10. European Rowan (Sorbus aucuparia) & NTF & 0.15 & 0.03 \\
11. Blackthorn (Prunus spinosa) & NTF & 0.09 & 0.03 \\
12. Cowberry (Vaccinium vitis-idaea) & NTF & 0.08 & 0.03 \\
13. Lily of the valley(Convallaria majalis) & TF & 0.05 & 0.03 \\
14. Oregon-grape (Mahonia aquifolium) & TF & 0.04 & 0.03 \\
15. Mezereon (Daphne mezereum) & TF & 0.03 & 0.03 \\
16. Herb Paris(Paris quadrifolia) & TF & 0.03 & 0.03 \\
17. Deadly Nightshade (Atropa bella- donna) & TF & 0.02 & 0.03 \\
18. Leatherleaf Viburnum(Viburnum rbytidophyllum) & TF & 0.02 & 0.03 \\
19. Common Snowberry (Symphoricarpos alba) & TF & 0.01 & 0.03 \\
20. Fly honeysuckle (Lonicera xylosteum) & TF & 0.01 & 0.03 \\
\hline
\end{tabular}

(Perceived toxicity) (Do you think that the fruit of the plant is toxic?), each on a five-point scale (e.g., $1=$ not at all, $5=$ extremely agree). Further, open-ended questions investigated 1. children's abilities to identify plants and 2. visiting nature (Are you frequently going to nature?). Correct identification was coded as 1 and incorrect as 0 . The latter question was coded dichotomously (yes/no).

The whole Cronbach's alpha for Willingness to eat toxic fruits, Confidence about plant species, Experiences and Perceived toxicity of the fruit was high (alpha $=0.79)$.

\section{RESULTS}

\section{Perception of toxic and non-toxic fruits}

Multivariate analysis of covariance (MANCOVA) with mean scores of four dependent variables (Willingness, Confidence, Experiences, Perceived toxicity) and three predictors (type of fruit [toxic/nontoxic], gender [boy/girl] and going to nature [yes/no]) was performed. The age of each child was treated as a covariate, thus yielding tests uncontaminated by individual differences in age (Isaac \& Michael, 1972). The effect of fruit toxicity and age significantly influenced dependent variables $(\mathrm{F}(4,220)=268.47$ and 8.90 , both $p<0.001)$. Gender and going to nature were not significant predictors $(\mathrm{F}(4,220)=0.75$ and 1.76 , both $\mathrm{p}>0.14$, respectively). Although some interaction effects were also significant, their power was generally low $(0.02<\mathrm{p}<0.05)$, we therefore do not describe them further in this paper. Our further analyses are restricted mostly to toxic plants because they pose a health risk to children.

The effect of fruit toxicity was very clear; children reported fewer experience of them, lower willingness to eat them and low ability to discriminate toxic fruits when compared to edible fruits (Table 1). Toxic fruits were also more frequently identified as inedible fruits and vice versa (Fig. 1).

The correlation between age (defined as a dependent variable) and children's perception of toxic and nontoxic plants (four variables listed in Fig. 1 defined as independent variables) was examined with a multiple regression model. As shown in Table 2, most of the significant associations were related to toxic plants. Using a backward linear regression model, only the willingness to eat toxic fruits remained in the model which suggests that this variable was strongly associated with the age of the children. 
This result suggests that younger children were more willing to eat toxic fruits compared to older ones (Fig. 2). Other significant associations showed in Table 2 mean that the older children reported more experiences with toxic fruits. Younger children were less sure whether toxic fruits are really inedible. Interestingly, there was no evidence that older children were more successful in distinguishing between toxic and non-toxic plants than younger children.

With regard to toxic fruits, simple correlations (Pearson) revealed that if a child thought that the fruit is toxic, their willingness to eat it decreased $(r=-0.65, p<$
0.001). Importantly, experiences with toxic fruits correlated with children confidence about which plant species it was $(\mathrm{r}=0.53, \mathrm{p}<0.001)$; however, experiences did not correlate with plant identification skills $(\mathrm{r}=0.12, \mathrm{p}=0.21)$. Moreover, children's confidence about plant species did not correlate with identification plant skills $(r=0.12, p=0.19)$. Children confidence about plant species marginally correlated with their willingness to eat toxic fruits $(\mathrm{r}=0.19, \mathrm{p}=$ 0.04). Importantly, children willingness to eat toxic fruits did not correlate with plant identification skills of children $(\mathrm{r}=-0.08, \mathrm{p}=0.41)$. Children's perceived

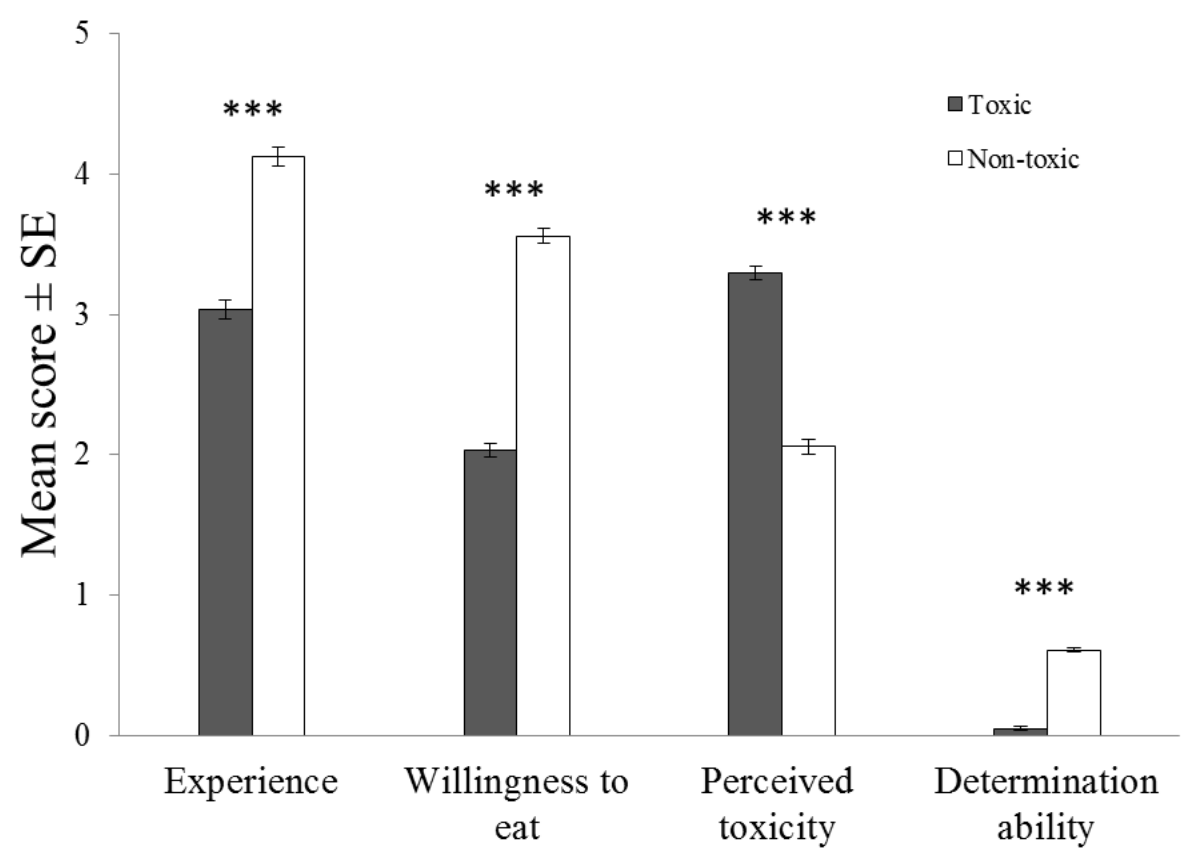

Figure 1. Differences in children's perception of toxic and non-toxic fruits. Asterisks (***) denote statistically significant difference $(\mathrm{p}<0.001)$

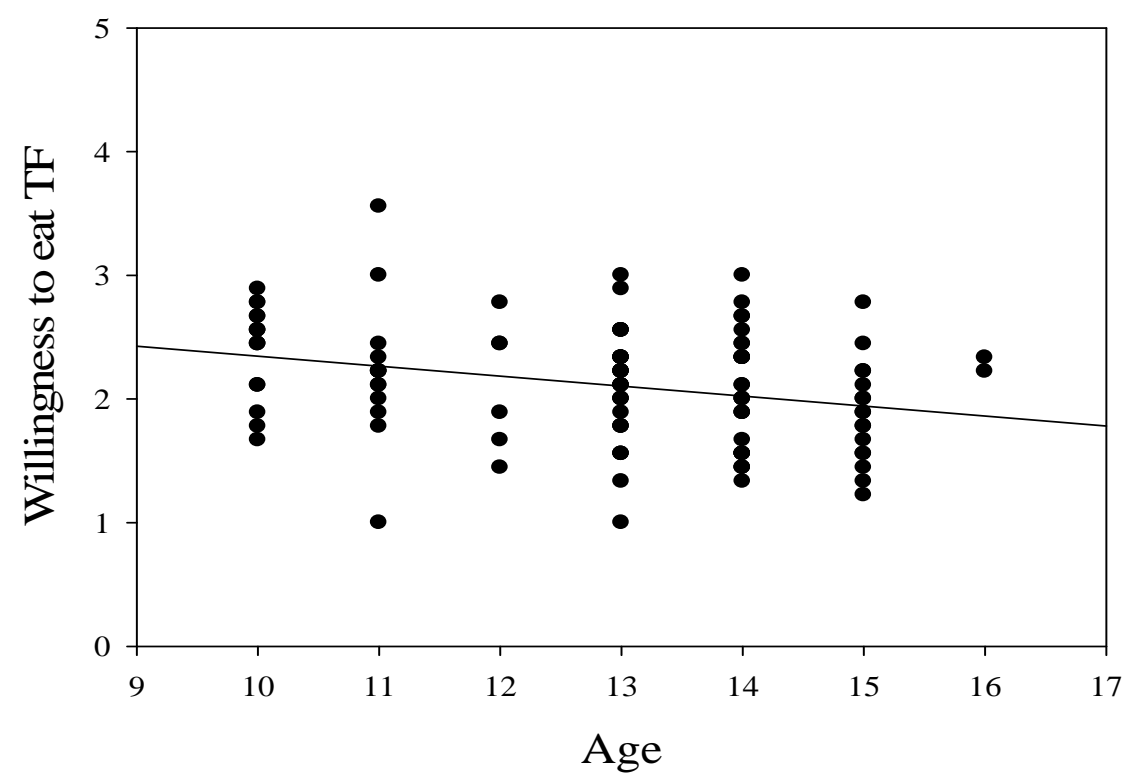

Figure 2. Relationship between age of children and their willingness to eat toxic fruits (TF) 
Table 2. Results of multiple linear regressions (forward stepwise method) on age of children as dependent variable

\begin{tabular}{lrrrc}
\hline & $\beta$ & SE of $\beta$ & $t(107)$ & $P$ \\
\hline Willingness to eat TF & -0.41 & 0.14 & -3.00 & 0.00 \\
\hline Experiences with TF & 0.28 & 0.12 & 2.30 & 0.02 \\
\hline Perceived toxicity of TF & -0.25 & 0.12 & -2.06 & 0.04 \\
\hline Confidence of TF & -0.20 & 0.09 & -2.29 & 0.02 \\
\hline Ability to identify NTF & 0.19 & 0.09 & 2.08 & 0.04 \\
\hline Willingness to eat NTF & -0.21 & 0.11 & -1.90 & 0.06 \\
\hline Experience with NTF & 0.17 & 0.12 & 1.37 & 0.18 \\
\hline Determination ability of TF & -0.11 & 0.10 & -1.10 & 0.27 \\
\hline TF = toxic fruits, NTF = non-toxic fruits & &
\end{tabular}

toxicity of fruits correlated neither with confidence about plant species, nor with plant identification skills $(\mathrm{r}$ $=0.03$ and -0.06 , both $\mathrm{p}>0.49$, respectively. These findings suggest that children might not recognize toxic and non-toxic toxic plants in the field.

\section{DISCUSSION}

Toxic fruits are commonly found in the nature, but their consumption can be harmful to people. Thus, plant identification skills and knowledge about toxicity of common plants is necessary. This study showed that toxic plants that could be identified both by leaves and fruits are much less understood than common non-toxic plants with edible fruits. Lower identification skills were associated with lower willingness to eat unknown fruits. Four predictions were tested:

1) Females will have better plant identification skills than males. From an evolutionary perspective, females were gatherers and males were predominantly hunters (Kaplan, 1996), thus females should be more knowledgeable about plants than males. This study did not support this prediction, because females scored similarly in their identification abilities score, willingness to eat toxic fruits, experiences with toxic plants and other variables. These results do not support with previous works showing greater preferences for botany by females (Dawson, 1983; Lohr et al., 2004; Hong, Shim, \& Chang 1998; Gatt et al., 2007; Prokop et al., 2007a,b; Schussler \& Olzak, 2008; Fančovičová \& Prokop, in press). However, as Prokop and Fančovičová (2010) pointed out, female preferences for plants are probably pronounced especially in aesthetic domain, due to the fact that bright colouring signalled food sources for people throughout evolutionary time (Heerwagen \& Orians, 1993). Further research might be therefore focused specifically on associations between ratings of attractiveness of edible and inedible fruits and willingness to consume them among males and females.
2) Younger children will be more willing to consume toxic fruits compared to their older counterparts. In agreement with previous reports about children's intoxication by poisonous plants (Jacobson et al., 1989; Litovitz et al., 1992), we supported this prediction by showing that younger children are more willing to eat toxic fruits. As far as we are aware, this is the first evidence showing that age-specific variation in willingness to eat toxic fruits exists in school children. Importantly, we did not find a positive association between identification skills of poisonous plants and age of children (the trend was reversed), suggesting that school does not play an important role in development of plant identification abilities of toxic plants. These results indirectly corroborate a study of Tunnicliffe and Reiss (2000) who found that home and direct observation are more important sources of knowledge about plants than school. Furthermore, experiences with toxic plants significantly increased with the age of the children, supporting the same idea: older children avoid eating toxic plants not because they have better factual knowledge about them, but most probably because they heard somewhere (e.g., from friends, parents, from TV) that these plants are toxic. What sources of information influence children's decision to avoid toxic plants however warrants further attention.

3) Children will show more experiences with nontoxic plants compared to toxic plants and consequently non-toxic plants will be identified more correctly than toxic plants. Although this prediction would be seen trivial at first glance, it was necessary to examine relative abilities of children to discriminate between toxic and non-toxic plants and their fruits. In line with this prediction, plants of which fruits are commonly used for consumption were more known than toxic plants with inedible fruits. However, both these groups of plants influence human survival, thus greater attention of teachers when teaching about toxic plants is required.

\section{CONSLUSION AND IMPLICATIONS}

Our study has the following implications for teaching botany:

1. School does not seem to play important role in children abilities to identify toxic plants. Greater effort to motivate children how (toxic) plants can be used in the pharmaceutical industry or how plants protect themselves by toxins against predators is required.

2. Children need to be educated about the role of non-profitable plants in ecosystems. Agricultural plants and their fruits are necessary for humans, but all other (although less known) plants are necessary for life on Earth.

3. Children seem to have poor plant identification skills. This finding is of special importance especially in the context of toxic plants. We showed that children's 
confidence about plant identification do not correlate with their identification score. However, if a child thought that he/she identified the plant correctly (albeit identification score of toxic plants was poor, see Table 1), willingness to eat the fruit significantly increased. Thus, children's incorrect knowledge of plants would result to consumption of toxic fruits.

4. Special attention should be paid especially to younger children because their willingness to eat toxic fruits is higher. Visiting natural habitats with toxic plants that resemble non-toxic ones would have harmful effects on children who were not instructed to avoid toxic plants. Paris quadrifolia is one of the best examples - it is toxic, but it has a poor identification score (see Table 1), and its fruits resemble the edible Vaccinium myrtillus. Moreover, both of these plants occupy the same habitats.

\section{Acknowledgement}

We would like to thank John Young for improving the English of the paper. Two anonymous referees provided helpful comments on the manuscript. This study was partly supported by projects VEGA no. 1/0124/11 and KEGA no. 175-006TVU-4/2010.

\section{REFERENCES}

Bebbington, A. (2005). The ability of A-level student to name plants. Journal of Biological Education, 32, 62-67.

Dawson, C.J. (1983). What science do students prefer? A study of some South Australian twelve year olds. School Science Review, 65, 133-136.

Fančovičová, J. \& Prokop, P. (2010). Development and initial psychometric assessment of the plant attitude scale. Journal of Science Education and Technology, 19, 415 - 421.

Fančovičová, J. \& Prokop, P. (in press). Plants have a chance: Outdoor educational programmes alter student's knowledge and attitudes towards plants. Environmental Education Research.

Gatt, S., Tunnicliffe, S. D., Borg, K. \& Lautier, K. (2007). Young Maltese children's ideas about plants. Journal of Biological Education, 41, 17-121.

Heerwagen, J. H. \& Orians, G. H. (1993). Humans, habitats, and aesthetics. In: Kellert SR, Wilson EO (eds) The Biophilia Hypothesis. Island Press, Washington, DC, 138-172.

Hong, J. L., Shim, K. C. \& Chang, N. K. (1998). A study of Korean middle school students' interests in biology and their implications for biology education. International Journal of Science Education, 20, 989-999.

Isaac, S. \& Michael, W. B. (1972). Handbook in research and evaluation. Robert Knapp, San Diego.

Jacobson, B. J., Rock, A. R., Cohn, M. S. \& Litovitz, T. (1989). Accidental ingestions of oral prescription drugs: a multicenter survey. American Journal of Public Health, 79, 853-856.
Kaplan, H. (1996). A theory of fertility and paternal investment in traditional and modern human societies. Yearbook of Physical Anthropology, 39, 91-135.

Lindemann-Matthies, P. (2005). "Loveable" mammals and "lifeless"plants: How children's interest in common local organisms can be enhanced through observation of nature. International Journal of Science Education, 27, 655-677.

Litovitz, T. L., Flagler, S. L., Manouguerra, A. S., Veltri, J. C. \&Wright, L. (1992). Recurrent poisonings among paediatric poisoning victims. Medical Toxicology and Adverse Drug Experience, 4, 381-386.

Lohr, V. I., Pearson-Mims, C. H., Tarnai, J. \& Dillman, D. A. (2004) .How urban residents rate and rank the benefits and problems associated with trees in cities. Journal of Arboriculture, 30, 28-35.

Plačková, S., Cagáňová, B. \& Kresánek, J. (2006). Epidemiology of poisonings in children. Lekárske obzory, 55, 296-297.

Plačková, S., Kresánek, J. \& Cagáňová , B. (2006). Plant intoxications. Lekárske obzory, 55, 298-300.

Polakoff, J.M., Lacouture, P. G. \& Lovejoy, F. H. (1984). The environment away from home as a source of potential poisoning. American Journal of Diseases Children, 138,1014-1017.

Prokop, P., Prokop, M. \& Tunnicliffe, S. D. (2007a). Is biology boring? Student attitudes toward biology. Journal of Biological Education, 42, 36-39.

Prokop, P., Tuncer, G. \& Chudá, J. (2007b). Slovakian students' attitudes toward biology. Eurasia Journal of Mathematics, Science \& Technology Education, 3, 287-295.

Schussler, E. E. \& Olzak, L.A. (2008). It's not easy being green: student recall of plant and animal images. Journal of Biological Education, 42, 112-118.

Tunnicliffe, S. D. \& Reiss, M. J. (2000). Building a model of the environment: How do children see plants? Journal of Biological Education, 34, 172-177.

Wandersee, J.H. (1986). Plant or animals-which do junior high school students' prefer to study? Journal of Research in Science Teaching, 23, 415-426.

Wandersee, J. H. \& Schussler, E .E. (2001). Toward a theory of plant blindness. Plant Science Bulletin, 47, 2-9. 